Portland State University

PDXScholar

$9-1-2011$

\title{
Limits to Sexual Reproduction in Geothermal Bryophytes
}

\author{
Sarah M. Eppley \\ Portland State University, eppley@pdx.edu \\ Todd N. Rosenstiel \\ Portland State University \\ Camille Brianne Graves \\ Portland State University \\ Estefanía Llaneza García \\ Portland State University
}

Follow this and additional works at: https://pdxscholar.library.pdx.edu/bio_fac

Part of the Biology Commons, and the Terrestrial and Aquatic Ecology Commons

Let us know how access to this document benefits you.

\section{Citation Details}

Sarah M. Eppley, Todd N. Rosenstiel, Camille B. Graves, and Estefanía Llaneza García. International Journal of Plant Sciences, Vol. 172, No. 7 (September 2011), pp. 870-878

This Article is brought to you for free and open access. It has been accepted for inclusion in Biology Faculty Publications and Presentations by an authorized administrator of PDXScholar. Please contact us if we can make this document more accessible: pdxscholar@pdx.edu. 
Int. J. Plant Sci. 172(7):870-878. 2011.

(c) 2011 by The University of Chicago. All rights reserved.

1058-5893/2011/17207-0004\$15.00 DOI: $10.1086 / 660884$

\title{
LIMITS TO SEXUAL REPRODUCTION IN GEOTHERMAL BRYOPHYTES
}

\author{
Sarah M. Eppley, ${ }^{1, *}$ Todd N. Rosenstiel, ${ }^{*}$ Camille B. Graves, ${ }^{*}$ and Estefanía Llaneza García* \\ *Portland State University, Center for Life in Extreme Environments, Department of Biology, \\ P.O. Box 751, Portland, Oregon 97207-0751, U.S.A.
}

\begin{abstract}
Previous research suggests that while sexual reproduction generally increases with environmental stress it may decrease with extreme stress, at the edge of eukaryotic life. In this study, we explored the limits to sexual reproduction in an extremophile, bryophyte system to ultimately understand the processes that limit sexual reproduction. We used field data from geothermal sites at Lassen Volcanic National Park, California, to demonstrate that sexual reproduction, as measured by the number of sporophytes per shoot, decreases with increasing environmental stress. We found that the number of sporophytes per shoot is positively correlated with distance from geothermal features. When Poblia nutans plants were transplanted to mesic conditions, high numbers of gametoecia and sporophytes were produced, regardless of where along the environmental stress gradient plants originated, suggesting that physiological stress rather than local adaptation is constraining sexual reproduction in this extremophile system. We discuss our results with respect to previous work on sex in extreme environments.
\end{abstract}

Keywords: bryophyte, reproduction, stress, temperature.

\section{Introduction}

Understanding the processes controlling the evolution and maintenance of sex is a key unresolved problem in evolutionary biology (Smith 1978; Burt 2000, 2002; Vamosi et al. 2003). While theoretical and laboratory-based studies suggest that sexual reproduction is favored in stressful environments (Iglesias and Bell 1989; Zeyl and Bell 1997; Greig et al. 1998; Grishkan et al. 2002), few studies have experimentally examined the relationship between environmental stress (either biotic or abiotic) and sexual reproduction in natural systems (e.g., Lively et al. 1998; West et al. 2002; Kis-Papo et al. 2003; Nedelcu and Michod 2003; Nedelcu et al. 2004) and fewer still have sought to determine what limits sexual reproduction in extremophiles living at the edge of eukaryotic life.

Recent research has rapidly advanced our understanding of the theoretical parameters underlying constraints on the evolution and maintenance of sex (e.g., Otto and Michalakis 1998; West et al. 1999; Vamosi et al. 2003); however, empirical work on biological constraints to sexual reproduction in stressful environments lags far behind these recent theoretical gains, mainly due to the lack of tractable experimental systems (Nedelcu and Michod 2003; David et al. 2005; Killick et al. 2006). Theory suggests that rates of sexual reproduction might increase in stressful, inhospitable, and crowded conditions because sex allows, among other things, (1) the production of offspring with allele combinations that may be more fit than the parental genotypes (see Burt 2000 for review) and (2) the operation of DNA repair mechanisms (e.g., Nedelcu and Michod 2003). If, in fact, sexual reproduction is beneficial, then we should find evidence of mechanisms

${ }^{1}$ Author for correspondence; e-mail: eppley@pdx.edu.

Manuscript received March 2011; revised manuscript received May 2011. facilitating successful sexual reproduction under high-stress conditions. Likewise, the need to identify the physiological limitations to sexual reproduction during extreme stress is necessary in order to distinguish whether limits to sexual reproduction are a consequence of physiological constraints on reproduction or instead reflect a selective optimum because sexual reproduction is disadvantageous in extreme stress environments (Kis-Papo et al. 2003).

In this study, our aim is to explore the limits to sexual reproduction in a geothermal bryophyte system. Bryophytes colonize the hottest terrestrial sites in geothermal areas worldwide, and these sites have varying moisture levels (Given 1980; Kappen and Smith 1980; Smith 1981; Bargagli et al. 1996; Burns 1997; Glime and Hong 1997; Elmarsdottir et al. 2003; Bonini et al. 2005; Convey and Lewis Smith 2006). Bryophytes are ecologically ubiquitous, occupying habitats on every continent and in nearly every terrestrial ecosystem (Shaw and Goffinet 2000). Bryophytes withstand extreme desiccation (Dilks and Proctor 1979), live at extreme temperatures (Given 1980; Burns 1997), and reproduce both sexually and asexually (Wyatt and Anderson 1984), making these organisms an ideal model system for examining the relationship between ecological stress and sexual reproduction. In addition, the presence of sporophytes is a well-established "marker" for realized sexual reproduction (i.e., successful fertilization) in bryophytes, making assessment of successful sexual reproduction feasible under field conditions (Mishler 1990). Despite obvious and intriguing experimental advantages, relatively few studies have examined the ecological or physiological limits to sexual reproduction in bryophyte systems (Shaw 2000).

Here we present research examining how patterns of sexual reproduction vary across an extreme environmental gradient within a well-characterized geothermal bryophyte community at Lassen Volcanic National Park (LVNP), California. We con- 
ducted extensive surveys of geothermal moss populations at LVNP surveying locations in which midday temperatures at the rhizoid-soil interface ranged from $15^{\circ}$ to $59^{\circ} \mathrm{C}$ and use this system to address these questions: (1) does sexual reproduction, as measured by the number of sporophytes per shoot, increase with environmental stress as has been shown for other eukaryotes; $(2)$ is the number of sporophytes per shoot correlated with either sexual expression or sex ratio of reproductive structures in geothermal bryophytes; and (3) does transfer of high-stress individuals to nonstress conditions alter the pattern of sexual reproduction in geothermal bryophytes? To answer these questions, we surveyed sexual structures in bryophytes in geothermal sites at LVNP and transferred plants from the field to the greenhouse to assess the role of local environment in constraining components of sexual reproduction in geothermal bryophytes.

\section{Material and Methods}

\section{Study System}

We have extensively surveyed for bryophytes around geothermal features in LVNP. Surveys in 2006 found bryophyte communities at Boiling Springs Lake $\left(40.435695^{\circ} \mathrm{N}\right.$, $-121.397145^{\circ} \mathrm{W}$; mean elevation of $\left.1799 \mathrm{~m}\right)$ and Devil's Kitchen $\left(40.44164^{\circ} \mathrm{N},-121.434331^{\circ} \mathrm{W}\right.$; mean elevation of $1854 \mathrm{~m}$ ) in the southeastern edge of the park but not at eight additional geothermal regions in the park where surveying was feasible. The chemical composition of these springs and geological systems of the areas has been well documented (Thompson 1982, 1983 ; Muffler et al. 1983; Synder 2005; Siering et al. 2006). At the elevation of these springs, the nongeothermal areas are primarily mixed coniferous forests of Pinus jeffreyi Balf. and Abies concolor (Gord. \& Glend.) Lindl. ex Hildebr., with few bryophytes except occasional Polytrichum juniperinum Hedw. patches in forest gaps. Besides plant communities in geothermal areas, the only nonconiferous communities in this region of the park are wet meadows (Pinder et al. 1997), and these have extensive bryophyte communities dominated by Philonotis fontana (Hedw.) Brid. and Brachythecium frigidum (Müll. Hal.) Besch.

From surveys in 2006, 2007, and 2008 at Boiling Springs Lake and Devil's Kitchen, we identified four primary bryophyte species growing in geothermally heated soils: Aulacomnium palustre (Hedw.) Schwägr., Campylopus introflexus (Hedw.) Brid., Ceratodon purpureus (Hedw.) Brid., and Pohlia nutans (Hedw.) Lindb., which all have been reported in geothermal sites in other areas of the world (Scott and Stone 1976; Gradstein and Sipman 1978; Given 1980; Söderström 1992; Bargagli et al. 1996; Burns 1997; Glime and Hong 1997; O’Brien 2000; Skotnicki et al. 2001,2002; Elmarsdottir et al. 2003; Smith 2005; Convey and Lewis Smith 2006; Chiarucci et al. 2008). In LVNP, Aulacomnium palustre grows exclusively around Boiling Springs Lake, and Poblia nutans grows exclusively around Devil's Kitchen. Also, the bryophytes Bucklandiella affinis (Schleich. ex Weber \& Mohr) Bednarek-Ochyra \& Ochyra and Ptychostomum pseudotriquetrum (Hedw.) J.R. Spence \& H.P. Ramsay occur in geothermal areas around Boiling Springs Lake but in fewer populations than the other bryophyte species. Of the six bryophytes growing in geothermally heated soils at Lassen, five have separate sexes, and $P$. nutans is hermaphroditic (Watson and Richards 1968; Crum 1973; Scott and Stone 1976). Just outside of the thermally heated areas, but in areas where the forest canopy remains open, Aulacomnium androgynum (Hedw.) Schwägr., Bucklandiella occidentalis (Renauld \& Cardot) Bednarek-Ochyra \& Ochyra, Dicranum tauricum Sapeh., and Grimmia montana Bruch \& Schimp occur. Thus, we have found 10 bryophyte species in and around these geothermal springs at LVNP. Angiosperms associated with the geothermal areas at LVNP include Dichanthelium acuminatum (Sw.) Gould \& C.A. Clark, Agrostis scabra Willd., and Mimulus guttatus DC.

\section{Sporophyte Survey 2006}

To determine the extent of sexual reproduction in bryophytes around geothermal features in LVNP, we sampled bryophytes in the field and counted sporophytes on the bryophytes we brought back to the lab. Sporophyte counts (including current sporophytes and indications of past sporophytes) maximize detection of sexual reproduction patterns in bryophytes (Stark et al. 2005) and have been used previously as an accurate indicator of frequency of realized sexual reproduction in bryophytes (Mishler 1990). In August 2006, we sampled bryophytes along nine line transects at Devil's Kitchen and four line transects at Boiling Springs Lake, with transects beginning near geothermal springs and fumaroles and ending farther away from geothermal features. We placed transects in all areas that we could safely reach in 2006. Depending on the size of bryophyte communities around each geothermal feature, transects were either $270 \mathrm{~cm}$, with $2.5 \times 2.5-\mathrm{cm}$ bryophyte mats collected every $30 \mathrm{~cm}$, or $100 \mathrm{~cm}$, with $2.5 \times 2.5$-cm bryophyte mats collected every $20 \mathrm{~cm}$. Temperature was measured at each mat collection location using a HH603A thermocouple with a 3-mm-diameter copperconstantan probe (Omega, Stamford, CT) placed at the interface between the moss rhizoids and the soil without rhizoids, generally a distinct boundary in the geothermal species. Measurement times for temperatures varied \pm 2 hours from midday.

The $2.5 \times 2.5-\mathrm{cm}$ bryophyte mat was our sampling unit for this survey and the subsequent survey in 2007. Bryophyte mats were collected, dried, and brought back to the lab at Portland State University. Bryophyte mats were rehydrated, the number of species was recorded, the species were identified, and the number of sporophytes (diploid tissue after fertilization) was counted on 300 gametophytic shoots per species, unless fewer shoots were available, in which case the total number of sporophytes on all shoots was counted. Gametophytic shoots within a bryophyte mat are expected to often represent individuals from the same genet, but some genetic diversity is possible (i.e., Van der Velde et al. 2001). Sporophyte counts included current cycle sporophytes and evidence of previous cycle sporophytes, following Stark et al. (2005). For the surveyed transects at Lassen in 2006, we surveyed eight bryophyte species (A. palustre, C. introflexus, C. purpureus, and $P$. nutans in the hotter areas, and $A$. androgynum, $B$. occidentalis, D. tauricum, and G. montana in the cooler sites), and we surveyed a mean of $279.3 \pm 5.90$ (SE) shoots per bryophyte mat collected. 


\section{Sexual Expression, Gametoecia Sex Ratios, and Sporophytes 2007}

To determine whether the low number of sporophytes we found in geothermal sites in 2006 was potentially caused by either (1) low production of sexual structures by gametophytes or (2) a skewed gametoecia sex ratio, we examined the number of sporophytes per shoot and the number and sex of gametoecia (perichaetia and perigonia, female and male sex organs, respectively, with clusters of modified leaves) per shoot in 2007. We examined individuals from populations of A. palustre, C. purpureus, C. introflexus, $P$. pseudotriquetrum, $P$. nutans, and $B$. affinis for gametoecia and sporophytes. We chose P. pseudotriquetrum and B. affinis despite these samples not appearing in our 2006 survey, because changes in the geothermal areas allowed us safe access to these species, and these species occurred in the hotter sites, growing with C. introflexus. For species with separate sexes, shoots were expected to have either male or female gametoecia, and we calculated the gametoecia sex ratio as the fraction of male gametoecia (male gametoecia divided by the total number of gametoecia). Pohlia nutans, the hermaphroditic species, could potentially have both male and female gametoecia on the same plant, and we calculated the gametoecia sex ratio in the same manner as with dioecious species (male gametoecia divided by the total number of gametoecia). Populations were defined for this study as discrete patches of a bryophyte species that varied in distance from one another from $20 \mathrm{~m}$ to more than $5 \mathrm{~km}$ within the Lassen geothermal area; two or three populations were sampled per species expect for $B$. affinis, for which only one population is present at LVNP. Thus, in 2007, we had more exhaustive coverage from more populations of the most common species at LVNP. For each population, transects were either $270 \mathrm{~cm}$, with bryophyte samples collected every $30 \mathrm{~cm}$, or $100 \mathrm{~cm}$, with bryophyte samples collected every $20 \mathrm{~cm}$, with the first sample of each transect taken in the moss patch closest to the geothermal site, as in 2006. Larger populations included more than one transect, separated by $100 \mathrm{~cm}$. We collected $2.5 \times 2.5$-cm bryophyte mats for each bryophyte sample, as previously. Samples were air-dried for storage until they were processed. Bryophyte mats were examined under a dissecting scope to determine the number of reproductive structures (gametoecia as well as counts of current and prior sporophytes) per shoot; 50 shoots were examined unless fewer shoots were present in a location, in which case the total number of reproductive structures on all shoots was counted (we examined 4744 shoots; $570-1126$ shoots per species).

\section{Common Garden Experiment with P. nutans}

To determine whether the low number of sporophytes along geothermal gradients was due to local adaptation or to physiological constraint under extreme stress, we collected $P$. nutans plants from along the geothermal gradient and grew them in a common garden environment in a greenhouse at Portland State University. We used P. nutans because it has a hermaphroditic sexual system, and thus, issues of sex ratio bias (i.e., too few males to produce sporophytes) will not confound our analysis. We used plant material collected from our 2007 transects with $P$. nutans (see above), and thus, information on the location of collected plants relative to geothermal features was recorded. The numbers of gametoecia and sporophyte per shoot were also recorded in our 2007 transect counts, and these data were used to compare the number of reproductive structures per shoot on $P$. nutans plants in the field to $P$. nutans plants acclimatized to growing in the greenhouse (see below). Fourteen sampled mats with $P$. nutans from three populations were randomly chosen for transfer to the greenhouse. Sample sizes were limited for this experiment because our park permit restricted us from collecting and maintaining larger collections of plants from these fragile geothermal habitats.

From the 14 randomly chosen $2.5 \times 2.5-\mathrm{cm} P$. nutans samples from the 2007 transects, we removed 20 shoots and planted them into two pots (10 shoots per pot) in the greenhouse $\left(15^{\circ} \pm 1.5^{\circ} \mathrm{C}\right.$; automatic misting watering system with twice-daily watering for $1 \mathrm{~min}$ per cycle). We allowed the shoots to reproduce through the protonemal stage to reduce variation due to previous environmental variation (Shaw 1986). Plants remained in the cultures for 2 yr. In the first year, mature sporophytes were removed to prevent colonization among pots.

In the second year, for the 12 pots from two populations that survived transplantation in the greenhouse, we recorded the numbers of gametoecia and sporophytes per shoot. We counted shoots randomly within pots until we recorded 50 nonexpressing shoots, and we recorded the number of expressing shoots (gametoecia) and shoots with sporophytes within those samples. On average 182.82 \pm 13.09 (SE) shoots were sampled in each pot for this analysis (50 nonexpressing shoots and the remainder with gametoecia or sporophytes). We used this method rather than a determined number of shoots because plants had several sexual stages (gametoecia and sporophytes) simultaneously and differed in the mix of these stages; $P$. nutans goes through multiple waves of reproduction (Clarke and Greene 1971), resulting in gametoecia and sporophytes overlapping.

\section{Data Analysis}

For the 2006 data, we used regressions to determine whether the number of sporophytes per shoots varied with (1) distance from geothermal features and (2) temperature at the rhizoid-soil interface across all species, rather than within species, as species distributions and frequencies within sites were not large. We did use generalized linear models (GLMs) to explore the effects of transect, population, species, site (Devil's Kitchen or Boiling Springs Lake), and interactions with these effects on our analyses, but we found they had no effect, perhaps because our samples sizes within species were not sufficiently large. For $P$. nutans, the only species that occurred at higher frequency across sampling locations, we used a one-way Welch's ANOVA to test whether sampled mats had more sporophytes per shoot in geothermal sampling locations rather than mats in nongeothermal sampling locations. Geothermal sampling locations $(G)$ were determined to be those locations with active, steaming hydrothermal fissures and were within $60 \mathrm{~cm}$ of geothermal features (pools or fumaroles). Nongeothermal sampling locations (NG) were all 
Table 1

Bryophyte Species Occurring within Geothermal Sites in Lassen Volcanic National Park and Midday Temperatures Measured at the Rhizoid-Soil Interface during Our 2006 Sporophyte Survey

\begin{tabular}{lccc}
\hline Species & $n$ & Mean temperature $\left({ }^{\circ} \mathrm{C}\right) \pm \mathrm{SE}$ & Temperature range $\left({ }^{\circ} \mathrm{C}\right)$ \\
\hline Bucklandiella occidentalis & 3 & $19.96 \pm .26$ & $19.50-20.39$ \\
Grimmia montana & 2 & $23.38 \pm 2.83$ & $20.55-26.22$ \\
Aulacomnium androgynum & 2 & $23.94 \pm 5.61$ & $18.33-29.55$ \\
Ceratodon purpureus & 11 & $26.92 \pm 3.78$ & $17.83-48.67$ \\
Dicranum tauricum & 2 & $28.67 \pm .22$ & $28.44-28.88$ \\
Pohlia nutans & 66 & $29.02 \pm .60$ & $19.83-54.55$ \\
Aulacomnium palustre & 20 & $39.10 \pm 2.93$ & $15.61-57.89$ \\
Campylopus introflexus & 10 & $43.94 \pm 2.63$ & $30.33-59.44$ \\
\hline
\end{tabular}

Note. Species are listed from low to high mean temperature.

other locations on the sampled transects. We chose a Welch's ANOVA because of heterogeneity of variances in our data (Day and Quinn 1989).

For the 2007 data, we had larger sample sizes within species, and thus we used a generalized linear model to determine the effect of transect (nested in species), species, distance from geothermal features along transects (a continuous variable), the number of gametoecia (a continuous variable), and interactions among these factors on the number of sporophytes per shoot (a continuous variable), for the three species in which we recorded both sporophytes and gametoecia present during the survey. Site (Devil's Kitchen or Boiling Springs Lake) was not significant and was not included in the analyses. We used a similar model to determine the effect of transect (nested in species), species, gametoecia sex ratio (a continuous variable), and interactions among factors, on the number of sporophytes per shoot for the subset of samples for which we had males and/or females present. No interactions were significant, and they were dropped from the analysis. We ran this model with and without $P$. nutans, which has combined sexes and thus is an outlier compared with the other moss species which all have separate sexes. However, we found no qualitative difference when we included P. nutans in the model compared to when it was excluded (these data are not shown). There were not sufficient degrees of freedom to include both transect and population in the models; as our sampling design was based on transect, we included transect and not population, although the models were qualitatively similar with either factor included.

In a comparison of plants grown in the greenhouse and field, initial ANOVA analyses determined that transect was not a significant factor. Because of heterogeneity of variance in analyzing our data, we dropped transect from our models and used Welch's ANOVA to determine the effect of growth environment (greenhouse vs. field) on (1) the number of gametoecia per shoot and (2) the number of sporophytes per shoot in P. nutans plants. For these analyses, we used field data from P. nutans plants collected during 2007, which were from the same populations for which we had greenhousegrown plants for comparison. We used mixed-model ANOVA to determine the effect of distance of sampling location from geothermal features (a fixed effect and a categorical distance variable coded as either geothermal [G] or nongeothermal [NG], as above described above for the P. nutans in the 2006 survey) and transect (a random effect) on (1) the number of gametoecia per shoot and (2) the number of sporophytes per shoot in $P$. nutans grown in the greenhouse experiment. All analyses were performed using JMP 8.0.2 (SAS Institute 2009).

\section{Results}

\section{Distribution and Sporophyte Survey 2006}

Aulacomnium palustre, Ceratodon purpureus, and Poblia nutans occurred most frequently in our survey, and occurred in a range of soil temperatures. Campylopus introflexus occurred frequently in our survey but only in high-temperature

(a)
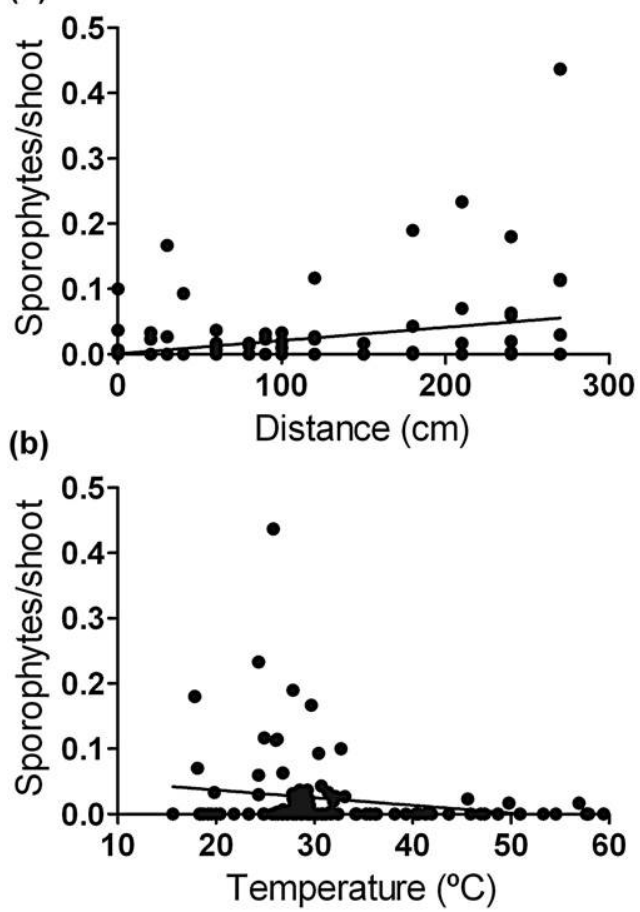

Fig. 1 Mean $( \pm S E)$ sporophytes per shoot versus distance from geothermal features $(a)$ and temperature at the rhizoid-soil interface (b) for bryophytes sampled at Lassen Volcanic National Park in 2006; $n=108$ mats sampled. 


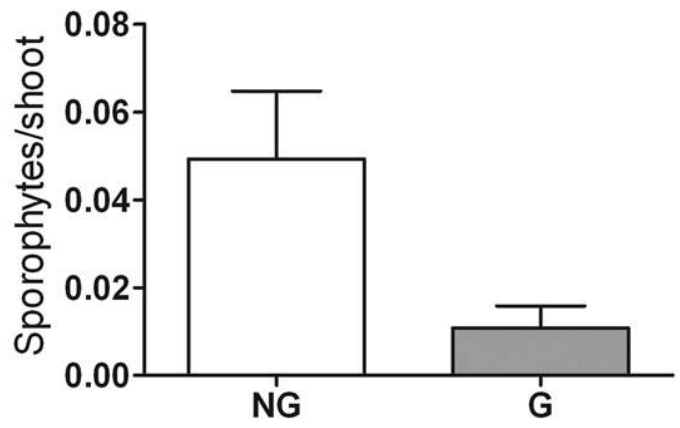

Fig. 2 Mean $( \pm \mathrm{SE})$ sporophytes per shoot for the moss Pohlia nutans from geothermal $(\mathrm{G})$ and nongeothermal (NG) locations in which the moss occurred in the 2006 survey; $n=35$ mats sampled in nongeothermal locations and 31 mats sampled in geothermal locations.

soils (table 1). Aulacomnium androgynum, Bucklandiella occidentalis, Dicranum tauricum, and Grimmia montana occurred rarely in open areas farther from geothermal features, in soils or on rocks that were less hot. Ptychostomum pseudotriquetrum and Bucklandiella affinis, two geothermal bryophyte species at LVNP, occurred less frequently in high-temperature soils and were absent from this survey in 2006.

Sporophytes were found in five moss species, A. palustre, C. purpureus, D. tauricum, G. montana, and P. nutans. The number of sporophytes per shoot increased significantly with distance from geothermal sites across LVNP bryophyte species in $2006\left(n=108\right.$ mats sampled; $P=0.002 ; R^{2}=0.09$; fig. 1). Similarly, the number of sporophytes per shoot was significantly influenced by temperature at the rhizoid-soil interface across species $(n=108$ mats sampled; $P=0.04$; $R^{2}=0.04$; fig. 2), with a sharp cutoff around $35^{\circ} \mathrm{C}$, above which few sporophytes were found. In Pohlia nutans, the one species to occur across many sampling locations in this survey, the number of sporophytes per shoot was significantly higher in nongeothermal sampling locations than in geothermal locations ( $n=66 ; F_{1,40}=5.61 ; P=0.02$; fig. 2 ).

\section{Sexual Expression, Gametoecia Sex Ratios, and Sporophytes 2007}

For the six bryophyte species we examined more extensively in 2007, sporophytes and gametoecia were found in three species, C. purpureus, P. nutans, and P. pseudotriquetrum, and gametoecia only were found on A. palustre and C. introflexus. Bucklandiella affinis plants were found to have neither sporophytes nor gametoecia. For the three species with both sporophytes and gametoecia, the number of sporophytes per shoot was significantly affected by distance from geothermal features, the number of gametoecia per shoot, and interactions between these two factors, as well as with species (table 2). Most importantly, the number of sporophytes per shoot was significantly affected by the interaction between distance and the number of gametoecia per shoot, with an increase in the number of sporophytes per shoot with an increase in the distance from geothermal features and an increase in the number of gametoecia per shoot. However, this relationship varied in strength among the three species, as the three-way interaction with species, distance, and gametoecia per shoot was significant in the analysis (table 2). In a separate analysis, which included only samples with expressing males and/or females, we found that the number of sporophytes per shoot was not affected by gametoecia sex ratio $(n=60$ mats sampled, $\left.P=0.74, \mathrm{df}=1, \chi^{2}=0.11\right)$, although transect $(P=0.02$, $\left.\mathrm{df}=8, \chi^{2}=18.77\right)$ and species $\left(P=0.006, \mathrm{df}=4, \chi^{2}=\right.$ 14.31) were significant in this analysis. Despite a measurable number of gametoecia per shoot in the field in most species (fig. $3 a$ ), there was little to no variation in gametoecia sex ratio within species (fig. $3 b$ ).

\section{Sexual Expression in the Greenhouse}

Transfer of $P$. nutans plants from the field to the greenhouse significantly increased the number of gametoecia and sporophytes per shoot $(n=35$ pots and bryophyte mats; $P=0.0004 ; F_{1,32}=15.49 ; P<0.0001 ; F_{1,21}=31.32$; respectively; fig. 4a). Neither distance from a geothermal feature nor transect of the original $P$. nutans sample had a significant effect on the number of gametoecia or sporophytes

Table 2

Results of a Generalized Linear Model Examining the Effect of Transect (Nested in Species), Species, Distance from a Geothermal Feature, Number of Gametoecia per Shoot, and Significant Interactions between Factors on the Number of Sporophytes per Shoot for Ceratodon purpureus, Pohlia nutans, and Ptychostomum pseudotriquetrum

\begin{tabular}{lccc}
\hline Source & $\mathrm{df}$ & $\chi^{2}$ & $P$ \\
\hline Transect (species) & 6 & 9.65 & .14 \\
Species & 2 & .77 & .69 \\
Distance & 1 & 16.79 & $<.0001$ \\
Gametoecia/shoot & 1 & 16.29 & $<.0001$ \\
Species $\times$ distance & 2 & 27.60 & $<.0001$ \\
Distance $\times$ gametoecia/shoot & 1 & 23.21 & $<.0001$ \\
Species $\times$ gametoecia/shoot & 2 & 18.16 & $<.0001$ \\
Transect $($ species) $\times$ distance & 6 & 23.19 & .0007 \\
Species $\times$ distance $\times$ gametoecia/shoot & 2 & 38.21 & $<. .0001$ \\
\hline
\end{tabular}

Note. The three bryophyte species surveyed at Lassen Volcanic National Park had both sporophytes and gametoecia in 2007. $n=55$ bryophyte mats sampled. Significant $P$ values are underlined. 
(a)

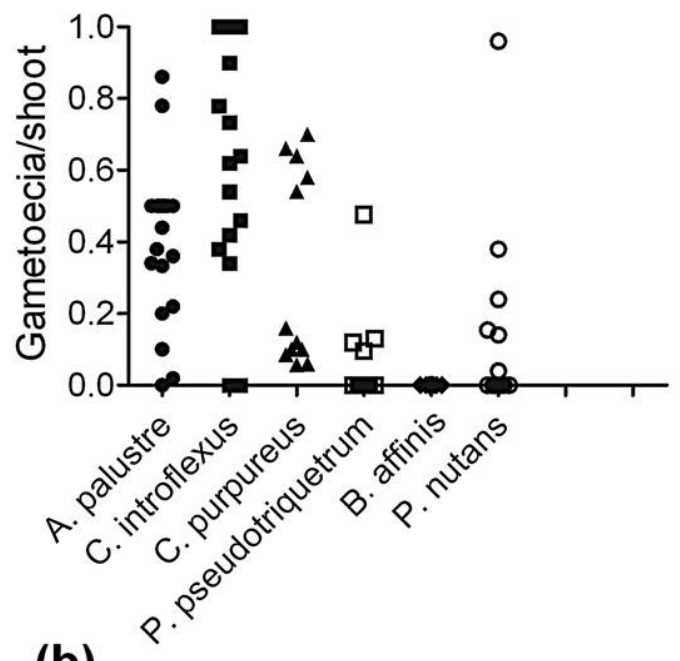

(b)

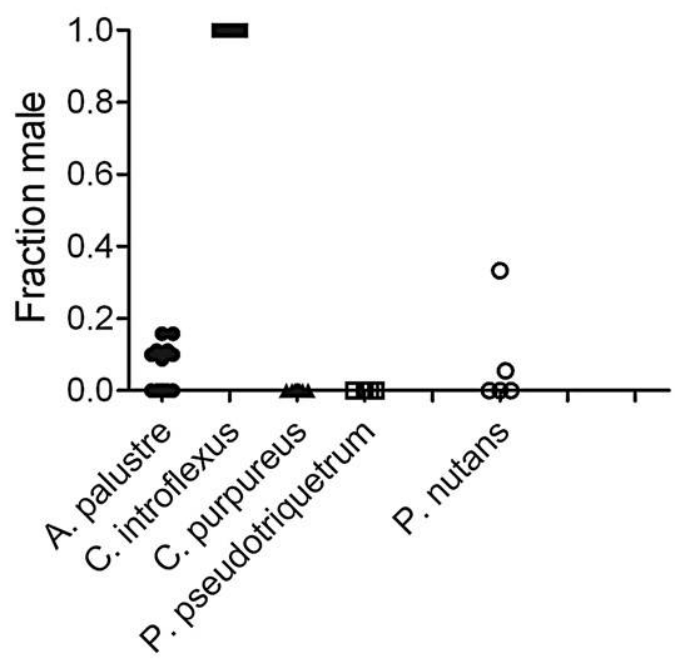

Bryophyte species

Fig. $3 a$, Mean $( \pm \mathrm{SE})$ gametoecia per shoots for geothermal bryophytes at Lassen Volcanic National Park (LVNP) in 2007; $n=$ 107 mats sampled. $b$, Fraction of shoots with gametoecia that are male for geothermal bryophytes at LVNP; $n=60$ mats sampled. Aulacomnium palustre (closed circles), Campylopus introflexus (closed squares), Ceratodon purpureus (closed triangles), Ptychostomum pseudotriquetrum (open squares), Bucklandiella affinis (closed diamonds), and Poblia nutans (open circles).

per shoot for plants grown in the greenhouse (table 3; fig. $4 b$ ). This contrasts to field-collected $P$. nutans samples in which distance from a geothermal feature had a significant effect on the number of sporophytes per shoot (table 2; fig. $4 c$ ), and the number of sporophytes per shoot was significantly affected by the interaction between the number of gametoecia per shoot and distance from geothermal features (table 2).

\section{Discussion}

In geothermal springs at LVNP, we found that while moss gametophytes are common around many springs in the area, the number of sporophytes is low near geothermal features and increases with distance away from such features and as temperature decreases. To determine at what stage sexual reproduction is being impacted in these geothermal sites, we collected data on both sex expression and sporophyte abundance across the LVNP gradients. Our data suggest that sporophyte production across these species was significantly affected by gameto-

(a)

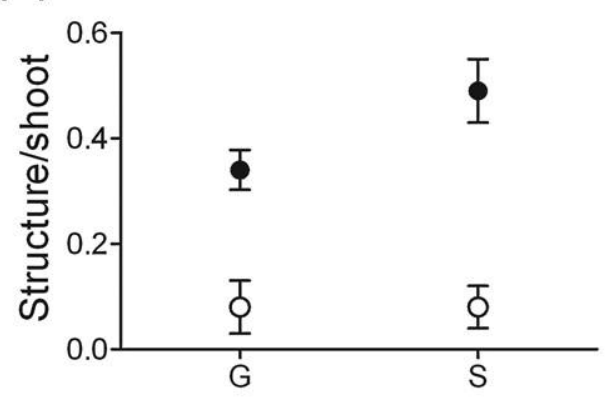

(b)

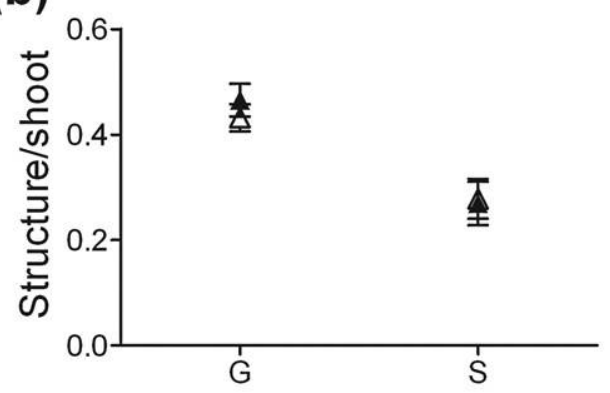

(c)

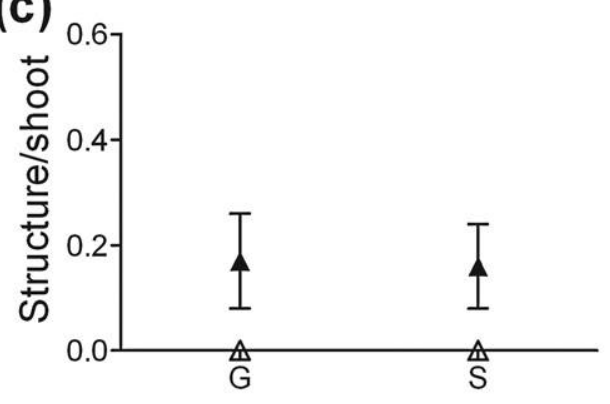

Structure type

Fig. 4 Mean $( \pm$ SE) gametoecia per shoot $(G)$ and sporophytes per shoot $(S)$ for Poblia nutans plants. $a$, Shoots grown in the greenhouse (filled circles) and shoots collected directly from the field (open circles); $n=35$ samples ( 12 pots from the greenhouse and 23 sampled mats from the field). $b$, Shoots grown in the greenhouse but originally collected from geothermal sampling locations (filled triangles) and from nongeothermal sampling locations (open triangles); $n=12$ pots. $c$, Shoots collected directly from the field from geothermal sites (filled triangles) and from nongeothermal sites (open triangles); $n=23$ sampled mats. 
Table 3

Results of Two-Way ANOVA Examining the Effect of Transect and Original Collection Distance from Geothermal Features (within $60 \mathrm{~cm}$ of Geothermal Features versus Farther from Geothermal Features)

\begin{tabular}{|c|c|c|c|c|c|c|}
\hline \multirow[b]{2}{*}{ Source } & \multicolumn{3}{|c|}{ No. gametoecia per shoot } & \multicolumn{3}{|c|}{ No. sporophytes per shoot } \\
\hline & $\mathrm{df}$ & $F$ & $P$ & $\mathrm{df}$ & $F$ & $P$ \\
\hline Transect & 1 & .04 & .85 & 1 & .32 & .59 \\
\hline Distance & 1 & 3.11 & .11 & 1 & .04 & .85 \\
\hline
\end{tabular}

Note. Data are for Pohlia nutans from Lassen Volcanic National Park growing in mesic conditions in the greenhouse at Portland State University. $n=12$ pots. There are no significant $P$ values.

ecia production, and thus in extreme-stress sites, few plants produced either sporophytes or gametoecia (fig. 4c). On transfer to more mesic greenhouse conditions, the correlation between the number of sporophytes and distance from geothermal feature disappears (fig. 4b), at least in Poblia nutans, suggesting that variation in the number of sporophytes among plants from the field is due to a physiological response rather than local adaptation. Below, we consider the correlation between sexual reproduction and environmental stress in this system.

\section{Sex and Geothermal Stress}

Theoretical and laboratory-based studies across a broad range of taxa demonstrate that sexual reproduction is favored in stressful environments (Iglesias and Bell 1989; Zeyl and Bell 1997; Greig et al. 1998; Grishkan et al. 2002). However, here we show that within geothermal bryophytes at LVNP the number of sporophytes per shoot increases with distance away from geothermal features and decreasing temperature (fig. 1a; table 2), suggesting that bryophytes are undergoing little sexual reproduction within the most extreme geothermal sites. Similar results have been found in a handful of other studies. For instance, Kis-Papo et al. (2003) showed sexual reproduction in fungi was severely reduced in the extreme salinity of the Dead Sea but increased with more moderate levels of stress (Kis-Papo et al. 2003). In mosses, Huttunen (2003) found that Pleurozium schreberi and P. nutans decreased sporophyte production as stress increased to extreme levels due to copper pollution. Also in mosses, Stark et al. (2005) found that in the extreme stress of the desert, Syntrichia caninervis decreased sporophyte production as stress increased. Our data from LVNP geothermal bryophytes supports these studies, indicating that sexual reproduction may decrease under extreme stress.

Temperature is negatively associated with sporophyte number in our 2006 data, suggesting that temperature may be a driver for the negative association between geothermal sites and sporophyte production in the LVNP bryophyte system. However, the $R^{2}$ value in our regression of sporophyte production and temperature was not high. Thus, other stresses imposed by the geothermal features, such as heavy metals in the soil, are potentially aiding in the decline in bryophytes and sexual reproduction found near geothermal features at LVNP.

\section{Gametoecia Expression and Sex Ratios}

Our data suggest that there is variation in gametoecia expression but not variation in gametoecia sex ratio across the geothermal stress gradient in the LVNP bryophytes. Our data show that the number of sporophytes per shoot is affected by an interaction between the number of gametoecia per shoot and distance from geothermal features (table 2), suggesting that the variation in the number of sporophytes per shoot with distance from geothermal features we observed at LVNP may be driven by variation in gametoecia formation along this same gradient. However, we also found that the number of sporophytes per shoot is significantly affected by a threeway interaction among species, distance, and the number of gametoecia per shoot. This three-way interaction indicates that for the three species measured, gametoecia expression may be behaving differentially across the geothermal stress gradient. For Ceratodon purpureus and P. nutans, gametoecia expression increases with distance away from the geothermal features, and this correlates with the number of sporophytes per shoot, but the majority of the sexual expression in C. purpureus occurs between 30 and $60 \mathrm{~cm}$ from geothermal features. For $P$. nutans, sexual expression occurs exclusively between 100 and $200 \mathrm{~cm}$ from geothermal features. This difference between the two species is most likely due to the heat tolerance and distributional variation. Ptychostomum pseudotriquetrum, the third bryophyte species in this analysis, has fewer gametoecia overall and a more even distribution of gametoecia across the geothermal stress gradient. Our data on variation in gametoecia expression across the geothermal stress gradient contradict previous data for $P$. nutans showing that reproductive shoots did not vary with distance from copper smelters, also presumably high-stress environments (Huttunen 2003).

For gametoecia sex ratios, we did find that the majority of species we examined had extremely female-biased sex ratios (four out of five species; fig. $3 b$ ), suggesting female-biased population sex ratios. However, we found little variation for gametoecia sex ratio within any of the species in geothermal areas across the gradient we sampled. These data suggest that while males and females may be differentially affected by stress, this differential did not change across the stress gradient, and differences in gametoecia sex ratio are not responsible for the variation in sporophyte production we measured across the gradient.

\section{Mechanisms for Limits on Sexual Reproduction}

Sexual reproduction may be limited in extreme environments either because (1) physiological constraints make sexual reproduction difficult or (2) only a few adaptive genotypes are 
selected as a selective optimum is reached and thus sexual reproduction is disadvantageous (Kis-Papo et al. 2003). Determining whether physiology or adaptation is responsible for the lack of sporophytes we find near geothermal features in geothermal bryophytes will be important to understanding sexual reproduction in extreme-stress systems and for potentially understanding the evolution of sex in a range of systems that may have evolved under extreme stress. We believe our data from $P$. nutans hint at what limits sexual reproduction in the geothermal bryophytes at LVNP. When we grow P. nutans plants from across the extreme stress gradient in mesic greenhouse conditions, plants produced both more gametoecia and sporophytes per shoot than were observed in natural populations of $P$. nutans growing across the geothermal gradient (fig. $4 a)$. Further, acclimatizing plants to greenhouse conditions allowed them to produce gametoecia and sporophytes regardless of whether they were originally growing in high-temperature locations near geothermal features or in low-temperature locations away from geothermal features (fig. 4b). In particular, despite the low sample size, the fact that plants from near geothermal areas produced gametoecia and sporophytes in the greenhouse when they had not in the field suggests that they are physiologically able to do so and are not genetically restricted from such production. These data differ from those of Jules and Shaw (1994), who transferred Ceratodon purpureus individuals from a high heavy-metal area to soil from low heavy-metal areas and did not see increases in gametoecia. Though not conclusive, our data do suggest that physiological constraints rather than local adaptation are limiting sexual reproduction in this system.

When plants are released from the constraints imposed by extreme stress they may reproduce sexually with little apparent trouble, as $P$. nutans did in our greenhouse experiment. It is possible that plants from the geothermal areas are simply adapted to be more plastic than plants from nongeothermal areas at LVNP, and a fully reciprocal experiment in growth chambers or the field is needed to determine whether this is the case. Field reciprocal transplants would be ideal but are not allowed within geothermal areas in the National Park and have been rarely attempted in mosses (e.g., Kooijman
1993; Frego and Carleton 1995; Mulligan and Gignac 2001; Cole et al. 2010).

\section{Conclusion}

The number of sporophytes in bryophytes is correlated with distance from geothermal features at Lassen Volcanic National Park, suggesting that sexual reproduction is reduced under extreme stress. These results support earlier work in fungi and mosses that showed a similar decrease in sexual reproduction in extreme-stress conditions (Huttunen 2003; Kis-Papo et al. 2003; Stark et al. 2005), despite a general trend toward an increase of sex with more moderate levels of stress (Iglesias and Bell 1989; Zeyl and Bell 1997; Greig et al. 1998; Grishkan et al. 2002). Future work in additional eukaryotes (e.g., algae and fungi from geothermal systems), would help determine whether the pattern holds, with sexual reproduction peaking at moderate to high levels of stress and then decreasing at the extreme edge of eukaryotic life. While this study analyzed rates of sexual reproduction using reproductive structures, additional data could be gained using molecular markers to determine genetic diversity across stress gradients with the assumption that increased sexual reproduction correlates with increased genetic diversity. Currently, genetic markers are limited for many of the geothermal bryophytes, but rapid development of microsatellite markers is making multiple-species, genetic structure studies a possibility in the near future.

\section{Acknowledgments}

We thank A. Brown, K. Halpin, C. Haaning, L. Lee, R. Richardson, and Maria Santiago for help in the lab and field; J. Christy, J. Shaw, and D. Wagner for help with bryophyte identification; and D. Percy for advice on geographic information system applications. We thank three anonymous reviewers for valuable comments on the manuscript. Research was supported by the $3 \mathrm{M}$ Corporation, Portland State University, and the National Science Foundation (DEB0743461 to S. Eppley).

\section{Literature Cited}

Bargagli R, PA Broady, DWH Walton 1996 Preliminary investigation of the thermal biosystem of Mount Rittmann fumaroles (northern Victoria Land, Antarctica). Antarct Sci 8:121-126.

Bonini I, F Casini, A Chiarucci, V de Dominicis 2005 The bryophyte flora of the geothermal field of Sasso Pisano (Pisa, Italy). Cryptogam Bryol 26:291-299.

Burns B 1997 Vegetation change along a geothermal stress gradient at the Te Kopia streamfield. J R Soc N Z 27:279-294.

$\rightarrow$ Burt A 2000 Perspective: sex, recombination, and the efficacy of selection-was Weismann right? Evolution 54:337-351.

$\rightarrow$ Butlin R 2002 The costs and benefits of sex: new insights from old asexual lineages. Nat Rev Genet 3:311-317.

$\rightarrow$ Chiarucci A, M Calderisi, F Casini, I Bonini 2008 Vegetation at the limits of vegetation: vascular plants, bryophytes and lichens in a geothermal field. Folia Geobot 43:19-33.

Clarke GCS, SW Greene 1971 Reproductive performance of two species of Poblia from temperate and sub-Antarctic stations under controlled environmental conditions. Trans Br Bryol Soc 6: $278-295$.

$\rightarrow$ Cole C, LR Stark, ML Bonine, DN McLetchie 2010 Transplant survivorship of bryophyte soil crusts in the Mojave Desert. Restor Ecol 18:198-205.

$\rightarrow$ Convey P, RI Lewis Smith 2006 Geothermal bryophyte habitats in the South Sandwich Islands, maritime Antarctic. J Veg Sci 17:529-538. Crum HA 1973 Mosses of the Great Lakes Forest, Michigan. 4th ed. University of Michigan, Ann Arbor.

$\rightarrow$ David JR, LO Araripe, M Chakir, H Legout, B Lemos, G Petavy, C Rohmer, D Joly, B Moreteau 2005 Male sterility at extreme temperatures: a significant but neglected phenomenon for understanding Drosophia climatic adaptations. J Evol Biol 18:838-846.

$\rightarrow$ Day RW, GF Quinn 1989 Comparisons of treatments after an analysis of variance in ecology. Ecol Monogr 59:433-463.

$\rightarrow$ Dilks TJK, MCF Proctor 1979 Photosynthesis, respiration and water content in bryophytes. New Phytol 82:97-114. 
Elmarsdottir A, M Ingimarsdottir, I Hansen, JS Olafsson, E Olafsson 2003 Vegetation and invertebrates in three geothermal areas in Iceland. Proceedings of the International Geothermal Conference, Reykjavik, September 14-17, pp 49-55.

$\rightarrow$ Frego KA, TJ Carleton 1995 Microsite tolerance of four bryophytes in a mature black spruce stand: reciprocal transplants. Bryologist 98:452-458.

Given DR 1980 Vegetation on heated soil at Karapiti, central North Island, New Zealand, and its relation to ground temperature. $\mathrm{N} \mathrm{Z} \mathrm{J}$ Bot 18:1-13.

Glime JM, WS Hong 1997 Relationships of geothermal bryophyte communities to soil characteristics at Thermal Meadow, Hotsprings Island, Queen Charlotte Islands, Canada. J Bryol 19:435-448.

$\rightarrow$ Gradstein SR, HJM Sipman 1978 Taxonomy and world distribution of Campylopus introflexus and C. pilifer (=C. polytrichoides): a new synthesis. Bryologist 81:114-121.

$\rightarrow$ Greig D, RH Borts, EJ Louis 1998 The effect of sex on adaptation to high temperature in heterozygous and homozygous yeast. Proc R Soc B 265:1017-1023.

$\rightarrow$ Grishkan I, AB Korol, E Nevo, SP Wasser 2002 Ecological stress and sex evolution in soil microfungi. Proc R Soc B 270:13-18.

$\rightarrow$ Huttunen S 2003 Reproduction of the mosses Pleurozium schreberi and Poblia nutans in the surroundings of copper smelters at Harjavalta, SW Finland. J Bryol 25:41-47.

Iglesias MC, G Bell 1989 The small-scale spatial distribution of male and female plants. Oecologia 80:229-235.

$\rightarrow$ Jules ES, AJ Shaw 1994 Adaptation to metal-contaminated soils in populations of the moss, Ceratodon purpureus: vegetative growth and reproductive expression. Am J Bot 81:791-797.

$\rightarrow$ Kappen L, CW Smith 1980 Heat tolerance of two Cladonia species and Campylous praemorsus in a hot steam vent area of Hawaii. Oecologia 47:184-189.

$\rightarrow$ Killick SC, AM Carlsson, SA West, TJ Little 2006 Testing the pluralist approach to sex: the influence of environment on synergistic interactions between mutation load and parasitism in Daphnia magna. J Evol Biol 19:1603-1611.

$\rightarrow$ Kis-Papo T, V Kirzhner, SP Wasser, E Nevo 2003 Evolution of genomic diversity and sex at extreme environments: fungal life under hypersaline Dead Sea stress. Proc Natl Acad Sci USA 100: 14970-14975.

$\rightarrow$ Kooijman AM 1993 On the ecological amplitude of four mire bryophytes: a reciprocal transplant experiment. Lindbergia 18:19-24.

$\rightarrow$ Lively CA, EJ Lyons, AD Peters, J Jokela 1998 Environmental stress and the maintenance of sex in a freshwater snail. Evolution 52: 1482-1486.

$\rightarrow$ Mishler BD 1990 Reproductive biology and species distinctions in the moss genus Tortula, as represented in Mexico. Syst Bot 15: 86-97.

Muffler LJ, NL Nehring, AH Truesdell, CJ Janik, MA Clynne, JM Thompson 1983 The Lassen geothermal system. US Geol Surv, Menlo Park, CA.

Mulligan RC, LD Gignac 2001 Bryophyte community structure in a boreal poor fen: reciprocal transplants. Can J Bot 79:404-411.

$\rightarrow$ Nedelcu AM, O Marcu, RE Michod 2004 Sex as a response to oxidative stress: a twofold increase in cellular reactive oxygen species activates sex genes. Proc R Soc B 271:1591-1596.

$\rightarrow$ Nedelcu AM, RE Michod 2003 Sex as a response to oxidative stress: the effect of antioxidants on sexual induction in a facultatively sexual lineage. Proc R Soc B 270:S136-S139.

O'Brien TJ 2000 Noteworthy collections: California. Campylopus introflexus (Hedw.) Brid. (Musci). Madrõno 46:113-114.

$\rightarrow$ Otto SP, Y Michalakis 1998 The evolution of recombination in changing environments. Trends Ecol Evol 13:145-151. $\rightarrow$ Pinder JE, GC Kroh, JD White, AMB May 1997 The relationships between vegetation type and topography in Lassen Volcanic National Park. Plant Ecol 131:17-29.

SAS Institute 2009 JMP for Windows. Release 8.0.2. SAS Institute, Cary, NC.

Scott GAM, IG Stone 1976 The mosses of southern Australia. Academic Press, New York.

$\rightarrow$ Shaw AJ 1986 A new approach to the experimental propagation of bryophytes. Taxon 35:671-675.

2000 Population ecology, population genetics and microevolution. Pages 369-402 in AJ Shaw, B Goffinet, eds. Bryophyte biology. Cambridge University Press, Cambridge.

Shaw AJ, B Goffinet, eds 2000 Bryophyte biology. Cambridge University Press, Cambridge.

$\rightarrow$ Siering PL, JM Clarke, MS Wilson 2006 Geochemical and biological diversity of acidic, hot springs in Lassen Volcanic National Park. Geomicrobiol J 23:129-141.

Skotnicki ML, R Bargagli, JA Ninham 2002 Genetic diversity in the moss Poblia nutans on geothermal ground of Mount Rittmann, Victoria Land, Antarctica. Polar Biol 25:771-777.

$\rightarrow$ Skotnicki ML, PM Selkirk, P Broady, KD Adam, JA Ninham 2001 Dispersal of the moss Campylopus pyriformis on geothermal ground near summits of Mount Erebus and Mount Melbourne, Victoria Land, Antarctica. Antarct Sci 13:280-285.

Smit CW 1981 Bryophytes and lichens of the Puhima Geothermal Area, Hawaii Volcanoes National Park. Bryologist 84:457-466.

Smith M 1978 The evolution of sex. Cambridge University Press, Cambridge.

$\rightarrow$ Smith RIL 2005 The thermophilic bryoflora of Deception Island: unique plant communities as a criterion for designating an Antarcitc Specially Protected Area. Antarct Sci 17:17-27.

Söderström L 1992 Invasions and range expansions and contractions of bryophytes. Pages 131-158 in JW Bates, AM Farmer, eds. Bryophytes and lichens in a changing environment. Clarendon, Oxford.

$\rightarrow$ Stark LR, DN McLetchie, BD Mishler 2005 Sex expression, plant size, and spatial segregation of the sexes across a stress gradient in the desert moss Syntrichia caninervis. Bryologist 108:183-193.

Synder JC 2005 Virus dynamics, archael populations, and water chemistry of three acidic hot springs in Yellowstone National Park. Montana State University, Bozeman.

Thompson JM 1982 Preliminary chemical studies of thermal waters in Lassen Volcanic National Park and vicinities. Trans Geotherm Res Counc 6:115-118.

1983 Chemical analyses of thermal and nonthermal springs in Lassen Volcanic Park and vicinity, California. US Geol Surv, Menlo Park, CA.

$\rightarrow$ Vamosi JC, SP Otto, SCH Barrett 2003 Phylogenetic analysis of the ecological correlates of dioecy in angiosperms. J Evol Biol 16:10061018.

$\rightarrow$ Van der Velde M, HJ During, L Van der Zande, R Bijlsma 2001 The reproductive biology of Polytrichum formosum: clonal structure and paternity revealed by microsatellites. Mol Ecol 10:2423-2434.

Watson EV, PR Richards 1968 British mosses and liverworts. Cambridge University Press, London.

$\rightarrow$ West SA, CM Lively, AF Read 1999 A pluralist approach to sex and recombination. J Evol Biol 12:1003-1012.

$\rightarrow$ West SA, SE Reece, BC Sheldon 2002 Sex ratios. Heredity 88:117-124. Wyatt R, LE Anderson 1984 Breeding systems in bryophytes. Pages 39-64 in AF Dyer, JG Duckett, eds. The experimental biology of bryophytes. Academic Press, London.

$\rightarrow$ Zeyl C, G Bell 1997 The advantage of sex in evolving yeast populations. Nature 388:465-468. 